\title{
Factors Associated with Sustained Attention during an Activity Intervention in Persons with Dementia
}

\author{
Ann Kolanowski $^{\mathrm{a}}$ Ann Bossen ${ }^{\mathrm{b}} \quad$ Nikki Hill ${ }^{\mathrm{a}}$ Edmarie Guzman-Velez ${ }^{\mathrm{c}}$ \\ Mark Litaker $^{\mathrm{d}}$ \\ ${ }^{a}$ School of Nursing, Pennsylvania State University, University Park, Pa., ${ }^{b}$ College of Nursing and \\ 'Department of Psychology, University of lowa, lowa City, lowa, and d School of Dentistry, University of Alabama, \\ Birmingham, Ala., USA
}

\section{Key Words}

Attention $\cdot$ Nursing homes $\cdot$ Nonpharmacological

intervention

\begin{abstract}
Background/Aims: Are the noncognitive factors of self-reported mood and personality related to sustained attention in nursing home residents with dementia during an activity intervention? Methods: Intervention data from a randomized clinical trial were used to address the aim of this project. Subjects were 128 nursing home residents who were assessed for mood, personality, behavioral indicators of attention, time on task and number of disengagements during an activity intervention. Results: More positive self-reported mood was associated with greater behavioral displays of attention during activities, greater time spent engaged in the activities and less disengagement. Conclusion: To our knowledge, this is the first study to report on the association of mood, personality and sustained attention in nursing home residents with dementia. While the findings are preliminary, they can be used to inform the design of future research.

Copyright $\odot 2012$ S. Karger AG, Basel
\end{abstract}

\section{Introduction}

Recreational activities are an essential component of quality care in the nursing home [1]. Engagement in activities that are tailored to the individual resident's needs can facilitate cognitive and physical functioning, and may prevent the downward spiral that often accompanies institutionalization [2]. Unfortunately, not all residents can be successfully engaged in recreational activities. While some disengagement may be due to lack of interest or poorly selected activities, impaired attention may also be a factor. This is especially true for residents with dementia because attention is a cognitive domain affected in these disorders [3].

Attention involves the cognitive states and operations needed to detect stimuli, select stimuli over 'noise', and manage resources for the detection and processing of competing stimuli. Three subtypes of attention have been identified: selective, sustained and divided attention [4]. Selective attention is the ability to focus on a stimulus to the exclusion of others, while divided attention allows sharing of attention resources, and sustained attention capacity is the maintenance of focus over time [5]. In both Alzheimer's disease (AD) and vascular dementia, selective and divided attentions are most vulnerable while sus-

Prof. Ann Kolanowski, PhD, RN, FAAN

School of Nursing, Pennsylvania State University

201 Health and Human Development East

University Park, PA 16802-6508 (USA)

Tel. +1 814863 9901, E-Mail amk20@psu.edu
2012 S. Karger AG, Basel

$1420-8008 / 12 / 0334-0233 \$ 38.00 / 0$

www.karger.com/dem 
tained attention is relatively preserved until later stages of the disease [6-8]. Impaired attention can result in slowed processing and reduced concentration, and negatively impact other aspects of cognitive and physical functioning [9]. For example, impairment in attention has been shown to adversely affect memory performance [10], locomotor function [11] and way-finding ability [12]. Given the rather pervasive influence of attention on overall function, impairment in sustained attention is likely to affect the ability to engage in nonpharmacological interventions such as recreational activities, the focus of the current study.

Nonpharmacological interventions are recommended as a first line of treatment for a number of behavioral and psychological symptoms of dementia [13]. Characteristically, many require some degree of sustained attention to exert their effect. We are just beginning to identify factors that may influence sustained attention in nursing home residents with dementia. Cohen-Mansfield et al. [14] tested a process model of engagement and found that higher engagement (operationalized as duration, attention, attitude and refusal) in activities was predicted by longer duration of modeling the activity, the presence of people in the environment, better cognitive status, better ability to carry out activities of daily living, and clarity of speech. Their findings illustrate the importance of better functional abilities and a supportive environment for improving attention. In a randomized clinical trial, our group found that behavioral displays of attention, time on task and level of participation were significantly improved when activities were tailored to personality style of interest [15]. This finding illustrates the interface between emotion and attention in that greater cognitive processing (attention) is directed toward aspects of the world that carry a higher degree of emotional significance (interest) [16].

The factors associated with attention in persons with dementia that have been identified to date can be used to improve prescription of activities so they promote sustained attention, but significant unexplained variance remains. Addressing this gap could make a significant contribution to health outcomes for nursing home residents in at least two ways. First, modifiable factors that improve sustained attention during activity interventions can be adjusted for improved outcomes. Secondly, factors that do not lend themselves to modification may be used to target interventions with increased precision to those individuals who are most receptive to recreational activity interventions.
In this study, we were interested in examining sustained attention within the context of a nonpharmacological activity intervention that aimed to improve the behavioral outcomes of agitation and passivity in nursing home residents with dementia. Mood and personality are two factors that have demonstrated an association with attention in healthy populations $[17,18]$, but they have not been fully examined in clinical populations. The current study was guided by this research question: Are the noncognitive factors of self-reported mood and personality related to sustained attention in nursing home residents with dementia during an activity intervention?

\section{Review of the Literature}

\section{Mood and Attention in Dementia}

Mood is a relatively enduring emotional state that has more permanence than an immediate emotional response evoked by a stimulus, such as fear or pleasure, but is not as pervasive, enduring or consistent as personality. Mood is generally thought of as having two dominant dimensions, positive and negative, but these dimensions are only modestly correlated $[19,20]$.

Negative mood is known to adversely impact divided attention in addition to information processing speed, motor functioning and cognitive flexibility [21, 22]. In addition, when depression is superimposed on dementia, there is a higher risk of adverse physical outcomes such as decreased functional status and physical health as well as increased mortality [23]. In persons with dementia, negative mood might be expected to attenuate the ability to engage in activities that require sustained attention.

In contrast, positive mood generally has an enhanced influence on cognition, specifically attention and executive function. Support for the impact of mood on cognition is based on the notion that positive mood stimulates increased dopamine levels in the brain resulting in better cognitive performance in some domains [24]. A positive mood state has demonstrated an enhanced influence on the ability to attend to a task [18], on memory [25], on creativity [24,26], on the ability to respond appropriately by inhibiting unchecked impulse responses [17], and on cognitive flexibility, including task switching $[24,26]$. Episodic memory formation and retrieval of information are enhanced if the present mood state is congruent with the mood one is attempting to recall [27].

Not all evidence is in support of a relationship between positive mood and positive cognitive outcomes. For example, Cabeza and Nyberg [28] found that attention was 
diminished when positive mood-related memories intruded a cognitive task. Similar findings were reported for deductive reasoning and planning $[17,29]$.

\section{Personality and Attention in Dementia}

Personality refers to an individual's relatively stable and unique intrinsic structure of thinking, feeling and behaving [30]. The predominant framework for the study of personality is the Five-Factor Model which consists of 5 broad personality domains: neuroticism, extraversion, openness to experience, agreeableness and conscientiousness [31,32].

Changes in personality have been reported as preclinical symptoms of $\mathrm{AD}[33,34]$. A recent systematic review determined that across studies, a consistent pattern of personality change is evident as dementia progresses: increased neuroticism, decreased extraversion and decreased conscientiousness [35]. Although changes in personality may occur, individuals tend to demonstrate rank order consistency regarding their overall personality profile, particularly in the earlier stages [36-40]. Two personality traits that may exert a behavioral effect on sustained attention in persons with dementia are conscientiousness and neuroticism.

Conscientiousness assesses the degree of organization, persistence and motivation an individual possesses and influences both the ability to control impulses as well as to be goal directed [41]. As the cognitive systems responsible for attention begin to deteriorate, the ability to retain goal-directed behavior may be compromised [42]. Among individuals already low in conscientiousness, dementia-related impairments may manifest as attentional problems earlier or to a greater extent than in those who are highly conscientious. Indeed, healthy older adults high in conscientiousness were less likely to develop AD compared to those low in conscientiousness [43]. Highly conscientious individuals, in spite of dementia progression, may be better able to remain focused on an activity in comparison to those who have been less conscientious during adult life [18].

Neuroticism is generally described as the chronic experience of distressing emotions as well as the inability to control impulses and react to stress in an adaptive manner $[41,44]$. High neuroticism is associated with many psychopathological disorders such as anxiety, mood and personality disorders [45-47]. Neuroticism is a biologically based predisposition which affects cognitive processing, in part, through attentional processes, leading to adverse effects in the controlled evaluation and correction of problematic cognitive and behavioral responses
[48]. It has also been found that individuals with certain psychopathologic personality traits (e.g. social dominance, callousness) exhibited diminished selective attention, perhaps due to difficulty in screening out irrelevant stimuli [49].

A recent study by Tse et al. [18] confirmed earlier results by examining differences in attention between healthy older adults and individuals with mild $\mathrm{AD}$ as well as the association of these differences with personality traits. Across three attention tasks (measuring attentional control, selective attention, and attention switching), individuals with mild AD displayed decreased attention compared to healthy older adults. Furthermore, the differences in attention were associated with both higher neuroticism and lower conscientiousness.

\section{Methods and Materials}

Intervention data from a randomized clinical trial that tested the efficacy of a tailored activity intervention for responding to behavioral symptoms in nursing home residents with dementia were used to address the aim of this project. The trial received approval from the Pennsylvania State University Institutional Review Board. The methods and procedures used in that study have previously been published [15]. The following is a brief summary of the protocol.

\section{Subjects and Setting}

One hundred and twenty-eight participants were recruited from 9 nursing homes in Pennsylvania and were those who: had a diagnosis of dementia according to DSM-IV criteria; a score of 8 or greater but less than 24 on the Mini-Mental State Examination (MMSE [50]); were English speaking; 65 years of age or older; had no new psychoactive drugs prescribed from baseline through to the final observation; no delirium or progressive, unstable medical, metabolic or neurological illness, and no history of Parkinson's disease, Huntington's disease, seizure disorder, stroke, alcoholism, drug abuse, head trauma with loss of consciousness or psychiatric illness preceding the onset of memory loss. Participants who met enrollment criteria and whose legally authorized representative consented to participation were enrolled in the trial. The 128 study participants were primarily female $(77 \%)$, Caucasian $(88 \%)$, with a mean age of 86.11 ( \pm 6.0 ) years, 12.26 $( \pm 3.1)$ years of education, and an MMSE score of $14.25( \pm 4.5)$.

\section{Procedure}

Following enrollment, participants were randomized into 1 of 4 activity conditions. A detailed description of the activity intervention has been published [15]. Briefly, each condition involved simple games and activities that were developed for nursing home residents [51], but were individually tailored to each participant's functional level, personality style of interest, both factors or neither factor. Examples of these activities include tether ball game, look inside purse and bingo. The Project Director assessed each participant's functional level using the MMSE and the Psychoge- 
riatric Dependency Rating Scale [52] and interviewed a knowledgeable family member to obtain a measure of personality style of interest using the NEO-Personality Inventory [41]. The personality traits of extraversion and openness define style of interest and are associated with preference for vocational as well as leisure activities. These data and the functional data were used in the prescription of activities. Based on prior theoretical [53] and preliminary work [54], it was hypothesized that activities tailored to both functional level and personality style of interest would result in less agitation and passivity and greater engagement because they meet individual needs related to function and interest.

Trained research assistants implemented participants' prescribed activities for up to $20 \mathrm{~min}$, twice a day for 3 weeks. Participants were allowed to disengage 4 times over the 20 -min session; at the fourth disengagement the activity was stopped. Immediately before each activity session, these same research assistants interviewed participants and assessed their self-rated mood using the Dementia Mood Picture Test [55]. At the end of each session, the research assistant recorded each participant's time on task, level of participation and count of the number of times the participant disengaged during the session. All activity sessions were videotaped to improve the reliability of behavioral outcome measures. Blinded research assistants then rated these tapes using standard instruments.

\section{Measures}

To capture a broad assessment of sustained attention during the activity session, several proxy measures were used: observation of prespecified behavioral displays of attention; the time each participant spent in activities (time on task), and the number of times the participant disengaged during the activity session. The observational assessment of attention behaviors was taken from video recordings of the activity sessions using the Affective Rating Scale [56]. This observational scale has descriptive indicators for 6 affective states, including attention. Attention was operationalized as: looks at, reaches for, touches, points at, nods, verbally responds, asks questions about activity, moves or verbally responds to music. Scores range from 1 to 5 ; higher scores indicate greater display of attention. The interrater reliability (ICC) for the attention subscale was 0.94 .

A stopwatch was used for measurement of time on task (possible score range: 0-20 min). A percentage agreement of 93.6 and a weighted kappa of 0.91 were obtained for time on task.

Disengagement was measured as a count of the number of times (0-4) that the participant displayed any disengaging behaviors during the activity session. These behaviors included: dozing, negative remarks about the activity, turning away from the interventionist/activity, asking to leave, leaving or attempting to leave the area.

Mood was measured immediately before the activity intervention using the Dementia Mood Picture Test[55], an instrument that measures self-reported positive and negative moods (bad, good, angry, sad, happy, worried). Each mood can receive a potential score of $0-2$, in intensity with higher scores representing a more positive mood. Correlation with the Montgomery-Asberg Dementia Rating Scale on which higher scores indicate greater depression is reported at 0.51 . We obtained an interrater reliability of 0.99 when using this instrument.

Personality was measured using Form R of the Revised NEO Personality Inventory, a 240-item Likert-type scale adapted for
Table 1. Outcomes by terms used in each model, estimates for terms and $\mathrm{p}$ values

\begin{tabular}{lcc}
\hline Independent variable & Estimate \pm SE & p value \\
\hline Attends & & \\
Mood & $3.26 \pm 1.6$ & 0.0475 \\
Neuroticism & $-0.09 \pm 0.3$ & 0.7550 \\
Conscientiousness & $0.37 \pm 0.3$ & 0.2422 \\
\hline Time on task & & \\
Mood & $4.26 \pm 1.7$ & 0.0129 \\
Neuroticism & $0.05 \pm 0.3$ & 0.8797 \\
Conscientiousness & $0.26 \pm 0.3$ & 0.4247 \\
\hline Number of disengagements & & \\
Mood & $-4.26 \pm 1.7$ & 0.0042 \\
Neuroticism & $-0.21 \pm 0.3$ & 0.4991 \\
Conscientiousness & $-0.11 \pm 0.3$ & 0.7100 \\
\hline
\end{tabular}

All models account for age, treatment assignment and mental status. Mood $=$ Score on the Dementia Mood Picture Test; neuroticism = score on the NEO Personality Inventory; conscientiousness $=$ score on the NEO Personality Inventory.

observer ratings [41]. This scale allows a comprehensive assessment of adult personality in the 5 domains of neuroticism, extraversion, openness, agreeableness and conscientiousness, and the 6 more specific facets that comprise each domain. Alpha coefficients for observer ratings on the domain scales range from 0.86 to 0.91 . A knowledgeable informant (usually a spouse or adult child) provided personality data during baseline assessment.

\section{Analysis}

Intervention period mood and the personality domains of neuroticism and conscientiousness were evaluated as predictors of behavioral displays of attention, time on task and number of times the subject disengaged during the activity session. Data were analyzed using a general linear model approach, controlling for age, mental status and treatment assignment. Observations were averaged within subjects, due to very low within-subject variability for a large portion of the sample. The values of the dependent variables were rank transformed, due to nonnormality of the sample distributions of the raw data. Initial univariate analyses were conducted with separate regression analyses for each of the independent variables. We then entered both predictor variables (mood and personality) into the model.

\section{Results}

In univariate analyses, greater behavioral displays of attention were positively associated with more positive mood $(\mathrm{p}<0.0001)$ and greater conscientiousness $(\mathrm{p}<$ $0.0001)$, and negatively associated with greater neuroticism $(p=0.0025)$. The number of times disengagement 
occurred over the 20 -min activity session was negatively associated with more positive $\operatorname{mood}(\mathrm{p}<0.0001)$ and greater conscientiousness $(\mathrm{p}=0.0237)$ such that, as mood and conscientiousness decreased, participants disengaged more often during the activity session. The total time participants spent engaged in the activity session was positively associated with more positive mood $(\mathrm{p}<$ $0.0001)$ and greater conscientiousness $(\mathrm{p}=0.0003)$ and negatively associated with greater neuroticism ( $\mathrm{p}=$ 0.0008).

Table 1 displays the results of the multivariate analyses. More positive mood was positively associated with greater displays of attention and greater time on task, and negatively associated with greater number of disengagements during activities. There were no significant relationships between neuroticism or conscientiousness and any of the dependent measures in the multivariate analyses.

\section{Discussion}

In this study we explored whether mood or the personality traits of conscientiousness and neuroticism had an effect on sustained attention in a group of nursing home residents with dementia. Having a more positive self-reported mood was associated with greater behavioral displays of attention during activities, greater time spent engaged in the activities and less disengagement, when we controlled for age, mental status and treatment assignment. Previous studies have demonstrated an effect of mood on attention. For instance, Rowe et al. [57] found that positive mood impaired selective visual attention. It has also been suggested that negative mood improves alerting efficiency during the completion of the Attention Network Test [58]. However, no study to our knowledge has explored the relationship between mood and sustained attention in nursing home residents with dementia. The current study aimed to fill this gap in the literature and found that positive mood can exert a positive effect on sustained attention in nursing home residents with dementia. One possible mechanism for this effect is that release of dopamine has been found to be stimulated by positive, but not negative, mood $[59,60]$. This release enhances motivation which may help sustain attention.

In order to explore the association between personality traits and sustained attention, a univariate analysis was conducted and we found that having a tendency toward depression, anger and fear (i.e. greater neuroticism) was associated with fewer displays of attention and less time on task during activities, while being more conscientious was associated with greater displays of attention, greater time on task and fewer disengagements during activities. These relationships make both theoretical and intuitive sense. High neuroticism is associated with psychological distress and maladaptive coping [61], which may contribute to decreased functional abilities in older adults [62]. It is likely that tendencies toward negative affective states may also influence activity participation. Additionally, stress-prone older adults are generally less motivated to perform [63] and more likely to display detrimental behaviors such as nonadherence to treatment [64]. Alternatively, high conscientiousness is associated with health-promoting behaviors and treatment success [65] which is thought to be influenced by improved adaptation to stressors and maintenance of everyday functional abilities [62].

Although univariate analyses supported the influence of personality on activity engagement, in multivariate analyses these relationships were no longer significant. We found no associations of either neuroticism or conscientiousness with any of our measures of attention in those models. In later stages of dementia, mood and mental status may be more important determinants of sustained attention than personality, an intrinsic structure that influences mood. Several theoretical frameworks $[53,66]$ speak to the importance of proximal factors, such as mood, and qualities of the physical and social environment in determining behavior in later stages of dementia. Personality, which continues to have some influence on behavior, may be less salient for predicting attentional ability in later stages of dementia as we found in this study.

Consistently with previous studies [67], we found a significant relationship between our control variable, mental status, and scores on attention outcomes (data not shown). This suggests that residents with dementia, despite their mood state, might have increased difficulty engaging in nonpharmacological interventions that require sustained attention as the disease progresses. From a clinical perspective, behavioral interventions may need to be implemented for shorter periods of time but at more frequent intervals for these individuals. In fact, research is needed to determine the dose of nonpharmacological interventions that produces positive outcomes across the dementia trajectory.

There are several limitations to this study owing to the fact that this was a secondary analysis of an existing data set. First, the sample was composed of nursing home residents and reflected the predominately female population 
in those settings. While this is an important group who frequently has problems with attention, the findings may not be generalizable to males or community-dwelling older adults. Furthermore we explored the association of mood and personality with sustained attention in residents for whom we did not differentiate types of dementia. Different types of dementia may affect sustained attention in different ways, and we were unable to determine that effect.

Despite these limitations, the findings indicate that personality traits may not exert a significant influence on sustained attention in residents with dementia. Better self-reported mood and higher mental status were positively associated with sustained attention during a nonpharmacological intervention. Helping nursing home residents engage in pleasant activities has been shown to promote quality of life in the nursing home by reducing the need for psychotropic drugs $[68,69]$, and future research should address factors that help these residents sustain their attention during these activities. While many personal and environmental factors likely influence attention, future research should also explore the neural mechanisms underlying the relationship between mood and sustained attention in persons with varying types of dementia.

\section{Acknowledgements}

This research was supported by a National Institute of Nursing grant No. R01 NR008910 awarded to the first author. N. Hill is a John A. Hartford Foundation Building Academic Geriatric Nursing Capacity (BAGNC) Scholar and thanks the BAGNC Award Program for its support.

\section{Disclosure Statement}

The funding organization had no role in the design and conduct of the study, analysis and interpretation of data, or preparation, review and approval of the manuscript.

\section{References}

$>1$ Buettner LL, Buckwalter K: Get your ACTivities together: new CMS regulations in longterm care. J Gerontol Nurs 2006;32:4.

-2 McConnell ES, Branch LG, Sloane RJ, Pieper CF: Natural history of change in physical function among long-stay nursing home residents. Nurs Res 2003;52:119-126.

-3 Belleville S, Chertkow H, Gauthier S: Working memory and control of attention in persons with Alzheimer's disease and mild cognitive impairment. Neuropsychology 2007; 21:458-469.

4 Robertson IH, Ward T, Ridgeway V, NimmoSmith I: The structure of normal human attention: the Test of Everyday Attention. J Int Neuropsychol Soc 1996;2:525-534.

5 Parasuraman R, Haxby JV: Attention and brain function in Alzheimer's disease: a review. Neuropsychology 1993;7:242-272.

-6 Hutchison KA, Balota DA, Ducheck JM: The utility of Stroop task switching as a marker for early-stage Alzheimer's disease. Psychol Aging 2010;25:545-559.

7 Perry RJ, Hodges JR: Attention and executive deficits in Alzheimer's disease. A critical review. Brain 1999;122:383-404.

-8 McGuinness B, Barrett SL, Craig D, Lawson J, Passmore AP: Attention deficits in Alzheimer's disease and vascular dementia. J Neurol Neurosurg Psychiatry 2010;81:157159.
9 Alescio-Lautier B, Michel BF, Herrera C, Elahmadi A, Chambon C, Touzet C, et al: Visual and visuospatial short-term memory in mild cognitive impairment and Alzheimer disease: role of attention. Neuropsychologia 2007;45:1948-1960.

10 Parasuraman R: Attentional functioning in Alzheimer's disease; in Morris RG, Becker JT (eds): Cognitive Neuropsychology of Alzheimer's Disease. Oxford, Oxford University Press, 2004, pp 81-102.

11 Sheridan PL, Solomont J, Kowall N, Hausdorff JM: Influence of executive function on locomotor function: divided attention increases gait variability in Alzheimer's disease. J Am Geriatr Soc 2003;51:16331637.

12 Chiu YC, Algase D, Whall A, Liang J, Liu HC, Lin KN, et al: Getting lost: directed attention and executive functions in early Alzheimer's disease patients. Dement Geriatr Cogn Disord 2004;17:174-180.

13 American Geriatrics Society and American Association for Geriatric Psychiatry: The American Geriatrics Society and American Association for Geriatric Psychiatry recommendations for policies in support of quality mental health care in US nursing homes. Am Geriatr Soc 2003;51:1299-1304.

14 Cohen-Mansfield J, Marx MS, Freedman L, Regier N, Thein K, Dakheel M: The comprehensive process model of engagement. Am J Geriatr Psychiatry 2011;19:859-870.
-15 Kolanowski A, Litaker M, Buettner L, Moeller J, Costa PT: A randomized clinical trial of theory based activities for the behavioral symptoms of dementia in nursing home residents. J Am Geriatr Soc 2011;59:10321041

16 Compton RJ: The interface between emotion and attention: a review of evidence from psychology and neuroscience. Behav Cogn Neurosci Rev 2003;2:115-129.

17 Martin EA, Kerns JG: The influence of positive mood on different aspects of cognitive control. Cogn Emot 2011;25:265-279.

-18 Tse CS, Balota DA, Yap MJ, Duchek JM, McCabe DP: Effects of healthy aging and early stage dementia of the Alzheimer's type on components of response time distributions in three attention tasks. J Neuropsychol 2010;24:300.

19 Carstensen LL, Pasupathi M, Mayr U, Nesselroade JR: Emotional experience in everyday life across the adult life span. J Pers Soc Psychol 2000;79:644-655.

20 Watson D, Clark LA, Tellegen A: Development and validation of brief measures of positive and negative affect: the PANAS scales. J Pers Soc Psychol 1988;54:1063-1070.

21 Baune BT, Suslow T, Engelien A, Arolt V, Berger K: The association between depressive mood and cognitive performance in an elderly general population - the MEMO Study. Dement Geriatr Cogn Disord 2006; 22:142-149. 
-22 Nakaaki S, Murata Y, Sato J, Shinagawa Y, Tatsumi H, Hirono N, et al: Greater impairment of ability in the divided attention task is seen in Alzheimer's disease patients with depression than in those without depression. Dement Geriatr Cogn Disord 2007 23:231-240.

-23 Mehta KM, Yaffe K, Langa KM, Sands L, Whooley MA, Covinsky KE: Additive effects of cognitive function and depressive symptoms on mortality in elderly community-living adults. J Gerontol A Biol Sci Med Sci 2003;58:M461-M467.

24 Phillips LH, Bull R, Adams E, Fraser L: Positive mood and executive function: evidence from Stroop and fluency tasks. Emotion 2002;2:12-22.

-25 Hill RD, Van Boxtel M, Ponds R, Houx P, Jolles J: Positive affect and its relationship to free recall memory performance in a sample of older Dutch adults from the Maastricht Aging Study. Int J Geriatr Psychiatry 2005; 20:429-435.

-26 Hirt ER, Melton RJ, McDonald HE, Harackiewicz JM: Processing goals, task interest, and the mood-performance relationship: a mediational analysis. J Pers Soc Psychol 1996;71:245-261.

-27 Baddeley A, Baddeley H, Bucks R, Wilcock G: Attentional control in Alzheimer's disease. Brain 2001;124:1492-1508.

28 Cabeza R, Nyberg L: Imaging cognition. II. An empirical review of 275 PET and fMRI studies. J Cogn Neurosci 2000;12:1-47.

29 Oaksford M, Morris F, Grainger B, Williams JMG: Mood, reasoning, and central executive processes. J Exp Psychol Learn Mem Cogn 1996;22:477-493.

- 30 Roberts BW, Mroczek D: Personality trait change in adulthood. Curr Dir Psychol Sci 2008; 17:31-35.

31 Costa PT Jr: Clinical use of the five-factor model: an introduction. J Pers Assess 1991; 57:393-398.

32 Wiggins JS: The multivariate paradigm; in Wiggins JS (ed): Paradigms of Personality Assessment. New York, Guilford Press, 2003.

- 33 Balsis S, Carpenter BD, Storandt M: Personality change precedes clinical diagnosis of dementia of the Alzheimer type. J Gerontol B Psychol Sci Soc Sci 2005;60:P98-P101.

- 34 Smith-Gamble V, Baiyewu O, Perkins AJ, Gureje O, Hall KS, Ogunniyi A, et al: Informant reports of changes in personality predict dementia in a population-based study of elderly African Americans and Yoruba. Am J Geriatr Psychiatry 2002;10:724-732.

35 Robins Wahlin T-B, Byrne GJ: Personality changes in Alzheimer's disease: a systematic review. Int J Geriatr Psychiatry 2010;26: 1019-1029.

36 Kolanowski AM, Whall AL: Life-span perspective of personality in dementia. Image J Nurs Sch 1996;28:315-320.

- 37 Twigg P, Burgener SC, Popovich A: Measurement and relevance of personality characteristics in persons with dementia: a longitudi- nal perspective. Res Theory Nurs Pract 2007; 21:13-31.

38 Chatterjee A, Strauss ME, Smyth KA, Whitehouse PJ: Personality changes in Alzheimer's disease. Arch Neurol 1992;49:486-491.

39 Dawson DV, Welsh-Bohmer KA, Siegler IC: Premorbid personality predicts level of rated personality change in patients with $\mathrm{Alz}$ heimer disease. Alzheimer Dis Assoc Disord 2000;14:11-19.

40 Strauss ME, Pasupathi M: Primary caregivers' descriptions of Alzheimer patients' personality traits: temporal stability and sensitivity to change. Alzheimer Dis Assoc Disord 1994;8:166-176.

41 Costa PT, McCrae RR: Revised NEO Personality Inventory and NEO Five-Factor Inventory: Professional Manual. Odessa, Psychological Assessment Resources, 1992.

42 Duncan J, Emslie H, Williams P, Johnson R, Freer C: Intelligence and the frontal lobe: the organization of goal-directed behavior. Cogn Psychol 1996;30:257-303.

43 Wilson RS, Schneider JA, Arnold SE, Bienias JL, Bennett DA: Conscientiousness and the incidence of Alzheimer disease and mild cognitive impairment. Arch Gen Psychiatry 2007;64:1204-1212.

44 McCrae RR: The five-factor model and its assessment in clinical settings. J Pers Assess 1991;57:399-414.

45 Tellegen A: Structures of mood and personality and their relevance to assessing anxiety, with an emphasis on self-report; in Tuma AH, Maser J (eds): Anxiety and Treatment. New York, Plenum Press, 1985, pp 681-706.

46 Eysenck H: Biological Basis of Personality. Secaucus, Lyle Stuart, 1967.

47 Widiger TA, Costa PT Jr: Personality and personality disorders. J Abnorm Psychol 1994;103:78-91.

48 Wallace JF, Newman JP: Neuroticism and the attentional mediation of dysregulatory psychopathology. Cognit Ther Res 1997;21: 135-156.

49 Sadeh N, Verona E: Psychopathic personality traits associated with abnormal selective attention and impaired cognitive control. Neuropsychology 2008;22:669-680.

50 Folstein MF, Folstein SE, McHugh PR: Minimental state: a practical method for grading the cognitive state of patients for the clinician. J Psychiatr Res 1975;12:189-198.

51 Buettner L: Simple pleasures: a multilevel sensorimotor intervention for nursing home residents with dementia. Am J Alzheimers Dis Other Demen 1999;14:41-52.

52 Wilkinson IM, Graham-White J: Psychogeriatric dependency rating scales (PGDRS): a method of assessment for use by nurses. Br J Med Hypn 1980;137:558-565.

53 Algase DL, Beck C, Kolanowski A, Whall A, Berent S, Richards K, et al: Need-driven dementia-compromised behavior: an alternative view of disruptive behavior. Am J Alzheimers Dis Other Demen 1996;11:10.
54 Kolanowski AM, Litaker M, Buettner L: Efficacy of theory-based activities for behavioral symptoms of dementia. Nurs Res 2005; 54:219-228.

55 Tappen RM, Barry C: Assessment of affect in advanced Alzheimer's disease: the Dementia Mood Picture Test. J Gerontol Nurs 1995;21: 44-46.

56 Lawton MP, Van Haitsma K, Klapper J: Observed affect in nursing home residents with Alzheimer's disease. J Gerontol B Psychol Sci Soc Sci 1996;51B:3-14.

57 Rowe G, Hirsh JB, Anderson AK: Positive affect increases the breadth of attentional selection. Proc Natl Acad Sci USA 2007;104: 383-388.

58 Jiang J, Scolaro AJ, Bailey K, Chen A: The effect of music-induced mood on attentional networks. Int J Psychol 2011;46:214-222.

59 Burgdorf J, Panksepp J: The neurobiology of positive emotions. Neurosci Biobehav Rev 2006;30:173-187.

60 Mitchell RLC, Phillips LH: The psychologi$\mathrm{cal}$, neurochemical and functional neuroanatomical mediators of the effects of positive and negative mood on executive functions. Neuropsychologia 2007;45:617-629.

61 Costa PT Jr, McCrae RR: NEO Inventories for the NEO Personality Inventory-3 (NEOPI-3), NEO Five-Factor Inventory-3 (NEOFFI-3), NEO Personality Inventory-Revised (NEO PI-R): Professional Manual. Lutz, Psychological Assessment Resources, 2010.

62 Chapman BP, Lyness JM, Duberstein P: Personality and medical illness burden among older adults in primary care. Psychosom Med 2007;69:277-282.

63 Judge TA, Ilies R: Relationship of personality to performance motivation: a meta-analytic review. J Appl Psychol 2002;87:797-807.

64 Hurtz GM, Donovan JJ: Personality and job performance: the Big Five revisited. J Appl Psychol 2000;85:869-879.

65 Bogg T, Roberts BW: Conscientiousness and health-related behaviors: a meta-analysis of the leading behavioral contributors to mortality. Psychol Bull 2004;130:887-919.

66 Smith M, Gerdner LA, Hall GR, Buckwalter KC: History, development, and future of the progressively lowered stress threshold: a conceptual model for dementia care. J Am Geriatr Soc 2004;52:1755-1760.

67 Cohen-Mansfield J, Marx MS, Regier NG, Dakheel-Ali M: The impact of personal characteristics on engagement in nursing home residents with dementia. Int J Geriatr Psychiatry 2009;24:755-763.

68 Cohen-Mansfield J, Marx MS, Freedman LS, Murad H, Thein K, Dakheel-Ali M: What affects pleasure in persons with advanced stage dementia? J Psychiatr Res 2012;46:402-406.

69 Wetzels R, Zuidema S, de Jonghe J, Verhey F, Koopmans R: Determinants of quality of life in nursing home residents with dementia. Dement Geriatr Cogn Disord 2010;29:189197. 